\title{
This Issue's Trigger Points Call for Discussion: Hypertonicity of the Quadratus Lumborum Muscle
}

\author{
Niki Munk, PhD, LMT, ${ }^{*}$ Practice Section Editor, IJTMB, \\ Whitney Lowe, LMT, ${ }^{2}$ Education Section Editor, IJTMB \\ ${ }^{I}$ Department of Health Sciences, Indiana University - IUPUI, Indianapolis, IN, USA, \\ ${ }^{2}$ Director, OMERI, Sisters, OR, USA
}

As noted in the introduction to the "Trigger Points" column in the June issue of the IJTMB (http://www. ijtmb.org/index.php/ijtmb/article/view/247), the Practice and Education Section Editors put out a call for discussion on the treatment of and education about a topical subject in therapeutic massage and bodywork. ${ }^{(1)}$ The current topic is Hypertonicity of the Quadratus Lumborum. Is this something you treat regularly? Struggle with? Teach treatment about? Share your knowledge and discuss the issues!

If you have something to say on the topic, please submit it - as appropriate - either to Practice (Dr. Niki Munk at nmumk@iu.edu) or Education (Whitney Lowe atwlowe97@gmail.com) by the end of December 2014. Submitted briefs for IJTMB's "Trigger Points" should be no longer than 300 words and include concise, yet detailed, information about how and why you use particular approaches and techniques when addressing the topic in either your practice or educational setting(s).

Submissions should address primary components that would be expected in order to understand and apply the knowledge. For example, descriptions of the primary treatment factors and contextual factors, such as any population-specific details, primary indications, and key contraindications (as appropriate), should be included. Contextual factors include the intention for the treatment(s) described and any necessary training information, such as for special training or therapeutic approach. Also relevant to your submission would be if there is a particular history to the approach, or if it is based in previous research (references would be appropriate, and would not count toward the word limit).

Respondents should also include a brief description of either their practice or education environment. For example, an introductory sentence or two may look something like this: I am a self-taught massage therapist with 25 -years of experience working with babies, children, and young mothers in a private, solo massage practice. I have taken continuing education courses through the Upledger Institute for CranioSacral therapy and lymphatic drainage and with the Barns Institute for myofascial treatment approaches.

The IJTMB Practice and Educator Editors will review the submitted briefs, draft a submission synopses that will include exemplars, and work together to provide commentary on the relevance or application of the synopses within practice, education, and possibly research. Based on expertise, a guest editor may be selected from the submissions to assist in the synopsis and commentary development, and a brief biography about the editor would be included in the edition.

Feedback about IJTMB "Trigger Points" is also welcome, as are suggestions for future topics.

We look forward to learning from you.

\section{COPYRIGHT}

Published under the CreativeCommons AttributionNonCommercial-NoDerivs 3.0 License.

\section{REFERENCES}

1. Lowe W, Munk N, Porcino A. Introducing IJTMB's Trigger Points: Topical dialogue amongst therapeutic massage \& bodywork practitioners and educators. Int $\mathrm{J}$ Ther Massage Bodywork. 2014;7(2):1-2.

Corresponding author: Niki Munk, $\mathrm{PhD}$, Department of Health Sciences, Indiana University-IUPUI, 1120 South Dr., Fesler Hall 115D, Indianapolis, IN 46202

E-mail:nmunk@iu.edu 